\title{
Retraction Note to: Location Privacy with Dynamic Pseudonym-Based Multiple Mix-Zones Generation over Road Networks
}

\author{
Qasim Ali Arain $^{1}$ (D) ZhongLiang Deng $^{1} \cdot$ Imran Memon $^{2}$ (D) $\cdot$ Asma Zubedi $^{3}$. \\ Farman Ali Mangi ${ }^{4}$
}

Published online: 10 May 2019

(c) Springer Science+Business Media, LLC, part of Springer Nature 2019

\section{Retraction Note to: Wireless Pers Commun (2017) 97:3645-3671 https://doi.org/10.1007/s11277-017-4690-5}

The Editor-in-Chief has retracted this article [1] because it shows significant overlap with previously published articles [2,3]. This article is therefore redundant. None of the authors agree to this retraction.

1. Arain, Q.A., Deng, Z., Memon, I. et al. Wireless Pers Commun (2017) 97: 3645. https://doi.org/10.1007/s11277-017-4690-5

2. Memon, I., Ali, Q., Zubedi, A. et al. Multimed Tools Appl (2017) 76: 24359. https://doi.org/10.1007/s11042-016-4154-Z

3. Arain, Q.A., Deng, Z., Memon, I. et al. China Communications (2017) 14(4): 89. https://doi.org/10.1109/CC.2017.7927579

Publisher's Note Springer Nature remains neutral with regard to jurisdictional claims in published maps and institutional affiliations.

The original article can be found online at https://doi.org/10.1007/s11277-017-4690-5.

Imran Memon

Imranmemon52@zju.edu.cn

$1 \quad$ Beijing University of Posts and Telecommunication, Beijing, China

2 College of Computer Science, Zhejiang University, Hangzhou, Zhejiang, China

3 School of Economics and Management, Beijing University of Posts and Telecommunication, Beijing, China

4 School of Electronic Engineering, University of Electronic Science and Technology of China, Chengdu, China 